\title{
Em busca do futuro perdido: a tarefa política da nova geração
}

\author{
Isabel Loureiro $^{1}$
}

ARANTES, Paulo. O novo tempo do mundo: e outros estudos sobre a era da emergência. São Paulo: Boitempo Editorial, 2014, 460 p.

A sensação de que o mundo capitalista, o nosso mundo, se encontra num fim de linha avançando em direção ao abismo tornou-se comum não só no campo da esquerda intelectual mas na sociedade em geral. O novo livro de Paulo Arantes - cujo título resume com precisão mais um capítulo do seu esforço permanente de renovar a Teoria Crítica procura dar estatuto teórico à época de transição que atravessamos às cegas, temendo nunca chegar sãos e salvos a porto seguro.

Antes de mais nada, uma observação preliminar. Estamos às voltas com um livro exigente, à espera de leitores atentos, sem preconceitos, dispostos a atiçar a imaginação. A tarefa do nosso Autor não é fácil. Um mundo em transformação, para o qual não existem ainda conceitos adequados, não pode ser apreendido nem traduzido numa forma simplificada. Contra a linguagem reificada, unidimensional e o consenso paralisante que torna quase indistinguíveis esquerda e direita, a ironia corrosiva, por vezes o sarcasmo demolidor. O trabalho do pensamento apresentado em toda a sua inteireza - uma das grandes qualidades de Paulo Arantes, também em suas exposições orais - remete à imagem do prisma que ao refratar a luz em várias direções compõe um panorama intensamente matizado. A própria construção dos ensaios, com o Autor dialogando consigo mesmo em longas digressões-excursos, é testemunho disso. O trabalho do pensamento pulveriza categorias petrificadas - o que já é uma forma de resistência contra a paralisia intelectual da esquerda - e convida a pensar junto. Leitor voraz de memória invejável, Paulo comenta livremente uma extensa bibliografia sobre as questões candentes do presente, intercalando esses comentários com reminiscências de romances, filmes, peças de teatro e assim por diante,

1 Professora aposentada do Departamento de Filosofia da Universidade Estadual Paulista Júlio de Mesquita Filho (Unesp, Marília, SP, Brasil). E-mail: belloureiro@uol.com.br 
num domínio impressionante do seu material, a ponto de por vezes provocar vertigem no leitor, curioso para ver aonde tudo isso vai dar. Não há dúvida de que ideias para muitos projetos de pesquisa podem ser tiradas daqui. É esse impulso generoso, buscando oferecer todos os elementos disponíveis para que o leitor pense por si mesmo, inclusive contra o próprio Autor, que torna essa meditação tão necessária num momento em que grande parte da esquerda não consegue ultrapassar o horizonte da próxima eleição.

Isto posto, encaremos a tarefa ingrata de resumir esse pensamento fecundo e original, puxando o nosso fio da meada. Estes ensaios e entrevistas - heterodoxamente filosóficos e materialistas - sobre a experiência intelectual do tempo presente, ao descreverem sem nenhuma benevolência as suas deformações, bem que poderiam ter como subtítulo, parafraseando Freud ao contrário, o mal-estar na barbárie. Mas afinal que mudanças aconteceram no mundo que permitem infligir tanto sofrimento indevido a parcelas cada vez maiores da população mundial, sem provocar nenhuma comoção visível? Que mutação histórica foi essa que tornou plausível a comparação, extravagante à primeira vista, entre o novo mundo do trabalho, vigente sob o neoliberalismo, e o trabalho forçado do sistema concentracionário nazista? Por que considerar o Brasil um capítulo local do estado de exceção permanente que assola o planeta?

A resposta se encontra no primeiro ensaio, que dá título e armação teórica ao livro, enquanto os outros expõem as figurações em que se traduz concretamente o Novo Tempo do Mundo. Sem poder entrar nos detalhes da reconstituição desse conceito, a ideia básica é que com a falência do horizonte de expectativas inaugurado com a Revolução Francesa - uma era de esperança em que se acreditava em mudanças fundamentais no futuro, à qual sucedeu, após o fim da Segunda Guerra Mundial, o consenso liberal-keynesiano - a humanidade, para falar como Wallerstein, encalhou num "período negro" de "caos sistêmico". Com o fim da URSS e da Guerra Fria, começou-se a perceber que "o horizonte do mundo encolhera vertiginosamente e uma era triunfante de expectativas decrescentes principiara”, um "tempo intemporal da urgência perpétua: este o Novo Tempo do Mundo" (p. 94). Em outros termos, o fim das grandes expectativas tem a data da morte do Welfare, com a reintrodução do medo econômico e da insegurança social em sociedades consideradas como de excessivo bem-estar. Vivemos em sociedades de risco, à beira do colapso ecológico, num permanente estado de alerta - não por acaso o princípio da responsabilidade e o da precaução fazem parte do debate -, indicando que o horizonte do mundo se estreitou. No resumo de Helga 
Novotny: "A categoria temporal do futuro foi simplesmente suprimida e substituída por uma outra, a do presente prolongado". Ou nas palavras do Autor: "Não basta anunciar que o futuro não é mais o mesmo, que ele perdeu seu caráter de evidência progressista. Foi-se o horizonte do não experimentado. Com isso o próprio campo de ação vai se encolhendo" (p. 96). Surge assim a grande questão: como "manter o horizonte de tal modo descomprimido que o 'não imaginado possa continuar imaginável'”? (p. 97) Ou seja, como fazer política, ou melhor, antipolítica, em oposição ao fervor gestionário e policial aliado da lógica da valorização, que hoje faz as vezes de política? Veremos que o último ensaio responde de algum modo a essa questão, seis anos depois abriu-se uma fresta por onde sopra um pequeno vento de utopia no presente prolongado.

Os três ensaios seguintes expõem as figuras contemporâneas do Novo Tempo do Mundo. O primeiro deles, "Sale Boulot", é um belíssimo escrito sobre o Holocausto e o atual mundo do trabalho, a partir do paralelo traçado pelo psicanalista francês Christophe Dejours entre o neoliberalismo dos vencedores de 1989 e o sistema concentracionário nazista. $\mathrm{O}$ aparato nazista de extermínio não teria funcionado sem a colaboração eficiente de milhões de indivíduos comuns consentindo em realizar zelosamente o seu trabalho sujo. De modo semelhante, o "novo mundo do trabalho moldado pela racionalidade neoliberal dominante", tendo virado um "imenso campo de experimentação e difusão da crueldade social", produziu, tal como na Alemanha nazista, uma "livre submissão defensiva" (p. 109). Foi o sofrimento social gerado no e pelo trabalho no período neoliberal que levou Dejours à reinterpretação de que o nazismo, como mobilização para o massacre, só se tornou possível porque todo o povo alemão foi posto a trabalhar. "Só o trabalho tornou possível organizar essa conduta de massa em proveito do horror (...). Em nome do trabalho, sempre se poderá valorizar uma desgraça. Este o segredo de toda "colaboração"' (p. 110). Exposta assim, sem mediações, pode parecer excessiva a comparação entre o trabalho genocida dos nazistas e a atividade compulsória de indivíduos livres atados a um ganha-pão, mas basta ler este ensaio formidável, que dá muito o que pensar, para convencer-se de que a "Era dos Extremos de Hobsbawm foi antes de tudo o Século do Trabalho Sujo" (p. 140).

É precisamente porque o horizonte do mundo encolheu - fruto da desintegração da sociedade salarial sob o comando do capital - que cresce a necessidade de manter imobilizadas as populações recalcitrantes. Estas vegetam em "Zonas de Espera” (título do terceiro ensaio) - presídios, campos de refugiados, agências de assistência social para desempregados em busca de trabalho, Faixa de Gaza, Cisjordânia 
ocupada, checkpoints espalhados pela Europa (mas não só) visando a impedir a entrada de imigrantes ilegais e, acrescentemos por nossa conta, ocupações de trabalhadores sem teto e sem terra - verdadeiras zonas de "suspensão do tempo" onde punir, humilhar, infligir sofrimento têm como objetivo a submissão necessária à administração "eficiente" dessa "humanidade residual que estorva" (p. 186). No turbocapitalismo da aceleração absoluta abriu-se um fosso entre o núcleo endinheirado correndo infatigavelmente para acumular capital e os párias sub-humanos com tempo de sobra para esperar "por coisa nenhuma" (p. 152). Aqui novamente o tempo é matéria para reflexão - tempo acelerado das elites versus espera imobilizadora dos pobres, a base material do conjunto sendo dada pela falência da sociedade do trabalho. Todas essas descrições do sofrimento inútil mundo afora conduzem a imaginação de volta à "quarentena infinita" (p. 188) dos campos de concentração nazistas. Diante dessa espera sem horizonte, que "corrompe sem fermentar" (p. 187) - a Questão Palestina não nos deixa mentir - talvez seja preciso concordar com o veredicto de que o "prazo de validade do teorema marxista - a humanidade só se defronta com os problemas que pode resolver - esteja vencido" (p. 82).

A falência da sociedade salarial, que no período fordista-keynesiano proporcionava alguma forma de coesão social, levou ao sequestro do futuro para as novas gerações, produzindo violência crescente dos dois lados: por parte do Estado, com toda a força de que dispõe - policial, legal e extra-legal - visando a garantir a segurança do capital, e por parte das periferias que protestam contra a injustiça em que vivem encurraladas. Esse estado de "emergência perene" (p. 225) é objeto da análise do quarto ensaio, "Alarme de incêndio no gueto francês", focado nos tumultos das periferias francesas em 2005, vistos como resultado do "longo processo de erosão dos direitos fundamentais" desde a década de 1980, que acabou por ganhar novo ímpeto com o 11 de setembro de 2001. Não nos enganemos, o caso francês é emblemático do que se passa no resto do mundo. O cinismo das "elites delinquenciais de hoje" (p. 244), que não acreditam mais em sua própria legitimidade e, por isso mesmo, ameaçam as populações recalcitrantes com a permanente emergência econômica, é um sinal da exaustão do capitalismo histórico, cuja fase atual - embora se refira à França, para bom entendedor meia palavra basta - Paulo Arantes caracteriza sarcasticamente como "ciclo de capitalismo de compadres" (p. 232) ou, mais debochadamente, "capitalismo de conivência entre cupinchas" (p. 211). Este o enquadramento em que a exacerbação do sentimento de insegurança se torna vital para a gestão, por parte do Estado, da "Era da Emergência". 
O restante do livro tem o Brasil como tema. Mas há uma mudança de tom entre as partes 3 e 4 (escritas entre 2007 e 2011) e o ensaio final, sobre os eventos de junho de 2013. Antes de 2013, o ano que não se encerrou, o sentimento era o de uma sociedade presa à maldição de uma conjuntura que não passa, a um horizonte de expectativa nulo sob a hegemonia cultural da direita. Embora os melhoramentos obtidos por milhões de trabalhadores pobres no Brasil não sejam de modo algum subestimados por nosso Autor, o que o incomoda é o outro lado da moeda, o "capitalismo brasileiro de cupinchas" (p. 312). Embora o Brasil de hoje seja muito diferente daquele de 1964 (para não falar do Brasil colônia), vivia-se então e vive-se agora no que talvez se possa caracterizar como "Estado Oligárquico de Direito" ou Estado "dual", que trata com liberalidade as "classes confortáveis" enquanto à ralé dispensa um tratamento "paternalista-punitivo". Análises comentadas por Paulo Arantes mostram como "Do Banco Central ao Código Tributário, passando pela Reforma Administrativa de 1967, a Constituição de 1988 incorporou todo o aparelho estatal estruturado sob a Ditadura. (...) Vem da Ditadura a consagração da lógica empresarial como prática administrativa do setor público" (p. 298). Ou seja, o país está atolado numa Transição que não passa.

Do lado macroeconômico, estilizando muito, na divisão internacional do trabalho de acumulação, coube ao Brasil, mais uma vez, atualizar a conhecida fórmula dialética do desigual e combinado, mas sem que daí saia qualquer impulso de superação. O desenvolvimento brasileiro juntou duas pontas aparentemente opostas: o país se converteu numa plataforma de valorização financeira e, ao mesmo tempo, aderiu ao "consenso das commodities". Nesse cenário, a ideia de segurança tornase fundamental. Tudo o que ameaça o desenvolvimento, entendido no sentido material, tem que ser afastado. Das populações no caminho dos megaeventos, passando pelos indígenas que se opõem às mega-represas, até os coletivos urbanos do contra, todos devem ser removidos da rota do progresso. Quer por bem, assimilando-os mediante os programas assistenciais de combate à pobreza e, no caso dos jovens, anulando-os com a conversa fiada do protagonismo juvenil. Quer por mal, quando teimam em ocupar as ruas, suprimindo-os com a conhecida coreografia da tropa de choque e das detenções em massa.

Com isso chegamos ao último ensaio do livro. "Depois de junho a paz será total" é o título irônico do tour de force que encerra a nossa viagem e que procura dar conta do vínculo entre pacificação e insurgência. Passado um ano, continuamos a dar tratos à bola para entender o que foi o "maior protesto de massa da história brasileira, com esta 
peculiaridade igualmente divisora de águas, a de que ele foi rigorosamente autoconvocado" (p. 378). Pulverizando os clichês propagados à direita e à esquerda - "baderna" de rua protagonizada por vândalos a serem devidamente dedetizados pelas forças da ordem, ou esquerdismo infantil de uma juventude desorganizada, sem direção, e que portanto dará em nada -, Paulo Arantes vai rastreando, na literatura recente sobre as classes populares urbanas no Brasil e em publicações de protagonistas dos eventos, ideias que lhe permitam construir hipóteses sobre a genealogia dos acontecimentos de junho. Dessa maneira, leva a cabo a interpretação mais original desses eventos até agora.

Se pusermos na panela de pressão brasileira os seguintes ingredientes, quase todos indigestos: o Programa de Pacificação das Favelas no Rio de Janeiro com suas UPPs, na verdade uma estratégia de guerra; a violência policial contra os moradores das periferias urbanas; as remoções forçadas exigidas pelos megaeventos; as políticas públicas que, ao incitar o empreendedorismo dos pobres, se, por um lado, canalizam sua energia para uma atividade governável, por outro, criam um sedimento reivindicativo à espreita para explodir; as lutas pela cidade, levadas a cabo por uma geração de "cidadãos insurgentes" exigindo a democratização do solo urbano; a "agonia do trabalho descartável, mostrando que o capitalismo como religião em sua forma contemporânea tornou-se um espantoso e interminável 'ritual de sofrimento"' (p. 396); as revoltas populares pelo transporte público; a síndrome da participação cidadã sem poder, etc. - todos temas analisados pelo Autor -, desconfiamos que esse conjunto de fenômenos faz sistema e explica, quem sabe, a "nova insurgência profanatória" (p. 413) que explodiu nas ruas em junho de 2013.

Não é possível retomar aqui passo a passo a exposição até chegar à atuação do Movimento Passe Livre (MPL), responsável pelo desencadeamento daqueles eventos memoráveis. Basta dizer que o movimento foi vitorioso graças a sua lucidez tática e estratégica - em forte contraste com a inabilidade política do prefeito e do governador. Os jovens (insurgentes?) do MPL souberam aliar o foco "reformista" numa única demanda, a redução de 20 centavos na tarifa, com uma exigência anticapitalista de desmercantilização da vida, a tarifa zero. Assim sendo, apresentaram um novo modelo - ainda que seja uma "herança sem receita" (p. 428) - para as lutas sociais no Brasil, ao mesmo tempo em que afrontaram a esquerda oficial, entorpecida pela realpolitik.

Paulo Arantes - assim como há exatos 50 anos o Marcuse de $O$ homem unidimensional - é visto frequentemente como adepto da crítica pela crítica; tal como Mefistófeles, o espírito que sempre nega, teria ficado 
preso ao pessimismo de uma sociedade sem oposição; ao não apresentar alternativas, só levaria à paralisia, etc. O leitor atento verá que, muito pelo contrário, a crítica radical não se esgota nela mesma, mas cria o sentimento da urgência necessário à luta.

No mundo da racionalidade neoliberal - em que a lógica do mercado se autonomiza e se estende para fora da esfera mercantil, estruturando a ação dos governantes, assim como a dos próprios governados no mais íntimo da sua subjetividade - a ideia de negação da negação ficou obsoleta, Marcuse dixit, para escândalo dos marxistas ortodoxos que teimam em não perceber que o realejo da dialética já não garante a superação imanente das contradições atuais numa etapa superior. Paulo Arantes concorda. De onde viria a ruptura com o sistema absurdo da acumulação pela acumulação quando as tecnologias de controle social, tudo leva a crer, produziram um "indivíduo absolutamente governável" e isso com sua própria e resoluta colaboração? Como romper com a pretensa normalidade governamental que reduz a política a uma perspectiva contábil?

O que os insurgentes de junho nos ensinam, nas palavras de John Holloway citadas pelo Autor, é que "Não faz mais sentido falar em paciência [grifo meu, nem mesmo do Conceito, P. A.] como uma virtude revolucionária ou falar sobre 'revolução futura'. Que futuro? Precisamos da revolução agora, aqui e agora. Tão absurdo, tão necessário. Tão óbvio" (p. 415). Hoje, a "utopia real" consiste na Grande Recusa desse sistema de normas, valores, práticas que mercantilizam todas as dimensões da vida, infligindo sofrimento e humilhação aos de baixo, e ao mesmo tempo temor de arriscar a ruptura com o eterno retorno do mesmo. Encarar esse estado de coisas e dar um passo adiante é a tarefa da nova geração. Que abriu uma porta em junho de 2013.

Um vento de utopia sopra em várias passagens do livro, mas vou me ater ao trecho final, quando Paulo comenta um texto da socióloga Regina Magalhães de Souza em que ela resume sua experiência de professora de sociologia numa dessas universidades particulares que vendem diplomas como se fossem bananas. A maioria dos alunos, trabalhadores pobres habitantes das periferias, vão descobrindo aos poucos que, em vez de serem apenas indivíduos atomizados lutando às cotoveladas por seus interesses próprios, fazem parte de uma coisa chamada "sociedade", que esta "lhes exige muito, mas não lhes oferece as condições de realizarem o que foi exigido". Ou seja, começaram a pensar e a fazer ligações entre suas experiências individuais e o contexto histórico e social. O que só foi possível porque, de alguma maneira, estavam fora da rede de integração pelo consumo, pelos movimentos sociais, partidos, 
sindicatos, protagonismo juvenil. A professora reconheceu muitos deles nas ruas de junho. Isso lhe dá o insight de que "a massa dos manifestantes era de indivíduos desamparados e sem discurso, mas que por isso mesmo foram capazes de perceber o caráter subalterno e de segunda categoria de sua inserção na sociedade, no mercado de trabalho, no mercado de consumo, no nível superior de ensino, na vida da metrópole [...]. [Eles] descobriram que coletivamente podem manifestar-se contra uma sociedade que tudo exige e nada cumpre" (p. 456). Para usarmos os termos de Silvia Viana, eles começaram a recusar as "porradas da vida", e por isso são imprescindíveis para a tarefa política da nova geração.

Paulo Arantes dedica seu livro "ao sangue bom que há treze anos circula nas noites de quarta” - os jovens estudantes que há mais de uma década frequentam o seminário livre animado por ele na Faculdade de Filosofia da USP. Ali fervilham ideias sobre as "coisas novas e ruins" do tempo presente, o Brasil em primeiro lugar. Incorporadas por ele à sua reflexão, essas ideias do contra, ao insuflar novo alento nas energias utópicas eclipsadas há muito, ajudam a manter viva a chama da redenção.

DOI: http://dx.doi.org/10.11606/issn.2316-901X.v0i59p389-396 